\title{
Primary thymus tumors: retrospective case analysis at a reference center in Latin America, 2011-2019
}

Diego F. Scarpetta-Gonzalez', Eliana Isabel Morales ${ }^{2,3}$, Luz Fernanda Sua ${ }^{3,4}$, Mauricio Velásquez ${ }^{3,5}$, Saveria Sangiovanni ${ }^{6}$ and Liliana Fernández-Trujillo ${ }^{3,7^{*}}$ (i)

\begin{abstract}
Background: Thymic tumors are unusual neoplasms, representing 0.2 to $1.5 \%$ of tumors in humans, but correspond to $20 \%$ of mediastinal tumors and $50 \%$ of those that occur in the anterior mediastinum. They tend to appear around the fourth and fifth decades of life without gender predilection. Up to 30\% of patients are asymptomatic, therefore many are incidentally diagnosed. Radical thymectomy is the treatment of choice with high survival rates when detected in the early stages.

Methods: This was a retrospective descriptive study, including 18 adult patients' diagnosis of thymic neoplasm, who were managed with surgical resection from 2011 to 2019. Information about demographics, clinical characteristics, imaging findings, surgical and medical management, plus histological findings was obtained and reported.

Results: 18 patients with thymic tumors were included, of which specific histologic studies reveled thymomas, carcinomas, neuroendocrine tumors, thymolipoma and thymic cyst. Mean age was 52.7 years, with a predominance of male population. The main symptom was dyspnea, followed by cough and chest pain. Paraneoplastic syndromes such as myasthenia gravis, aplastic anemia and Cushing syndrome were reported. 89\% of cases were treated by radical thymectomy alone, while only 2 cases required chemotherapy and radiotherapy. There were no surgical complications. Mean hospital stay length was 11.9 days, with only 1 mortality during hospital admission. 5-year survival rate was $81 \%$.

Conclusions: The treatment of choice is radical thymectomy, which has been shown to positively impact patient mortality. Early detection is key to improve patient outcomes.
\end{abstract}

Keywords: Thymic neoplasm, Thymoma, Thymic carcinoma, Video-assisted thoracoscopy, Radical thymectomy

\footnotetext{
* Correspondence: liliana.fernandez@fvl.org.co;

lilianafernandeztrujillo@fvl.org.co

${ }^{3}$ Faculty of Health Sciences, Universidad Icesi, Calle 18 \# 122-135, Cali

7600032, Colombia

${ }^{7}$ Department of Internal Medicine, Pulmonology Service, Interventional

Pulmonology, Fundación Valle del Lili, Avenida Simón Bolívar. Carrera 98 \#

18-49, Tower 6, 4th Floor, 7600032 Cali, Colombia

Full list of author information is available at the end of the article
}

C C The Author(s). 2021 Open Access This article is licensed under a Creative Commons Attribution 4.0 International License, which permits use, sharing, adaptation, distribution and reproduction in any medium or format, as long as you give appropriate credit to the original author(s) and the source, provide a link to the Creative Commons licence, and indicate if changes were made. The images or other third party material in this article are included in the article's Creative Commons licence, unless indicated otherwise in a credit line to the material. If material is not included in the article's Creative Commons licence and your intended use is not permitted by statutory regulation or exceeds the permitted use, you will need to obtain permission directly from the copyright holder. To view a copy of this licence, visit http://creativecommons.org/licenses/by/4.0/ The Creative Commons Public Domain Dedication waiver (http://creativecommons.org/publicdomain/zero/1.0/) applies to the data made available in this article, unless otherwise stated in a credit line to the data. 


\section{Background}

Thymus tumors include neoplasms that arise from or differ from thymic cell constituents, comprising thymic epithelial tumors (thymomas, thymic carcinomas, neuroendocrine tumors), germ cell, lymphoid and hematopoietic, and mesenchymal tumors [1].

They are unusual neoplasms, representing 0.2 to $1.5 \%$ of tumors in humans, with an incidence of 0.1 to 0.5 cases per 100,000 individuals per year in the United States [2]. However, thymus tumors correspond to $20 \%$ of mediastinal tumors and $50 \%$ of those that occur in the anterior mediastinum [3]. They tend to appear around the fourth and fifth decades of life without gender predilection [4]. Approximately 25 to $30 \%$ of patients are asymptomatic, and are incidentally diagnosed, $50 \%$ being revealed by chest computed tomography (CT) [5]. When symptomatic, $40 \%$ of patients present with local symptoms triggered by mass effect (mainly chest pain, cough, snoring and dyspnea), 30\% report constitutional symptoms (weight loss, fever and night sweats), and 30$50 \%$ present with paraneoplastic syndromes $[4,6]$.

When the tumor is found by imaging modalities, of which contrast enhanced chest CT scan is the image of choice, the next steps are to characterize and stage the lesion, stablishing the degree of local invasion, the presence of lymphadenopathy and distant dissemination. Hence allowing the identification of patients who benefit from surgical management as compared to those who require other types of interventions [7]. In fact, the National Comprehensive Cancer Network (NCCN) guidelines classifies thymic tumors into three clinical categories: localized and resectable, locally advanced and unresectable, and metastatic; a combination of surgical protocols, radiotherapy and/or chemotherapy is warranted for the last two groups, while surgery is sufficient to treat the first category [8].

The objective of this study is to describe the demographic, clinical, radiological and histological characteristics of 18 patients with thymic tumors, who were taken to surgical tumor resection at Fundación Valle del Lili, a high complexity institution in Cali-Colombia, between 2011 and 2019.

\section{Methods}

This was a descriptive study based on clinical records of adult patients ( $\geq 18$ years old) who had a diagnosis of thymic neoplasm and were treated at our institution from 2011 to 2019. Information about demographics, clinical characteristics, imaging findings, surgical and medical management, plus histological findings was obtained. Patients were followed up to December 2019 and the survival curve was estimated using the KaplanMeier method. This study was approved by the ethics committee of our institution and was developed according to the Helsinki Declaration of 1964.

\section{Results}

\section{Demographic and clinical characteristics}

18 patients with diagnosis of thymic tumor were treated at our institution between 2011 and 2019; 11 male (61\%) and 7 females $(39 \%)$, with a mean age of 52.7 years $( \pm 16.6)$. 3 patients were asymptomatic (16.6\%). The remaining patients presented with constitutional symptoms $(61.1 \%)$ of which the most common was weight loss, or local symptoms (55.5\%) being the most frequent dyspnea, cough and chest pain in decreasing order. Paraneoplastic syndromes presented in $27.7 \%$ of patients, of which 2 had myasthenia gravis, 1 had a non-myastheniform neuromuscular disorder, 1 had red blood cell (RBC) aplasia and 1 had Cushing syndrome (Table 1).

\section{Radiological characteristics}

Chest imaging showed that 14 cases $(77.7 \%)$ involved the anterior mediastinum, 2 cases (11\%) compromised the left parahiliar region, 1 case (5.5\%) the middle mediastinum and 1 case (5.5\%) the left prevascular space (Fig. 1). The longest side of the tumors had a mean of $7.5 \mathrm{~cm}$ ( \pm 5.37). Tumor density was reported in 13 patients; it was heterogenous in $53.8 \%$ of patients with calcifications in $30.8 \%$. Only one patient presented with pleural effusion.

Most patients had a localized disease; using the Masaoka-Koga and TNM staging system for malignant tumors, 13 patients $(76.4 \%)$ were classified as stage I for both systems, 3 cases (17.6\%) stage IV and IVB respectively ( 1 patient had metastasis in deep intrathoracic/cervical lymph nodes and 2 had distant metastasis) and 1 patient $(6.2 \%)$ was classified as stage III (MK) or stage II (TNM) cancer due to invasion of the pericardium. In one patient the information was not available (Table 2).

Table 1 Baseline clinical characteristics of patients

\begin{tabular}{ll}
\hline Demographics & $\mathbf{( N = 1 8 )}$ \\
\hline Male sex (\%) & $11(61 \%)$ \\
Age $-\mathrm{yr}^{\mathrm{a}}$ & $52.7( \pm 16.6)$ \\
Clinical characteristics & \\
Asymptomatic patients (\%) & $3(16,6 \%)$ \\
Constitutional symptoms (\%) & $11(61,1 \%)$ \\
Weight loss & $4(22,2 \%)$ \\
Fever & $1(5,5 \%)$ \\
Night sweats & $0(0 \%)$ \\
Paraneoplastic syndromes (\%) & $5(27,7 \%)$ \\
Neuromuscular & $3(16.6 \%)$ \\
RBC aplasia & $1(5.5 \%)$ \\
Cushing syndrome & $1(5.5 \%)$ \\
\hline
\end{tabular}

${ }^{a}$ Value corresponds to mean and standard deviation (SD) $R B C$ Red blood cell 


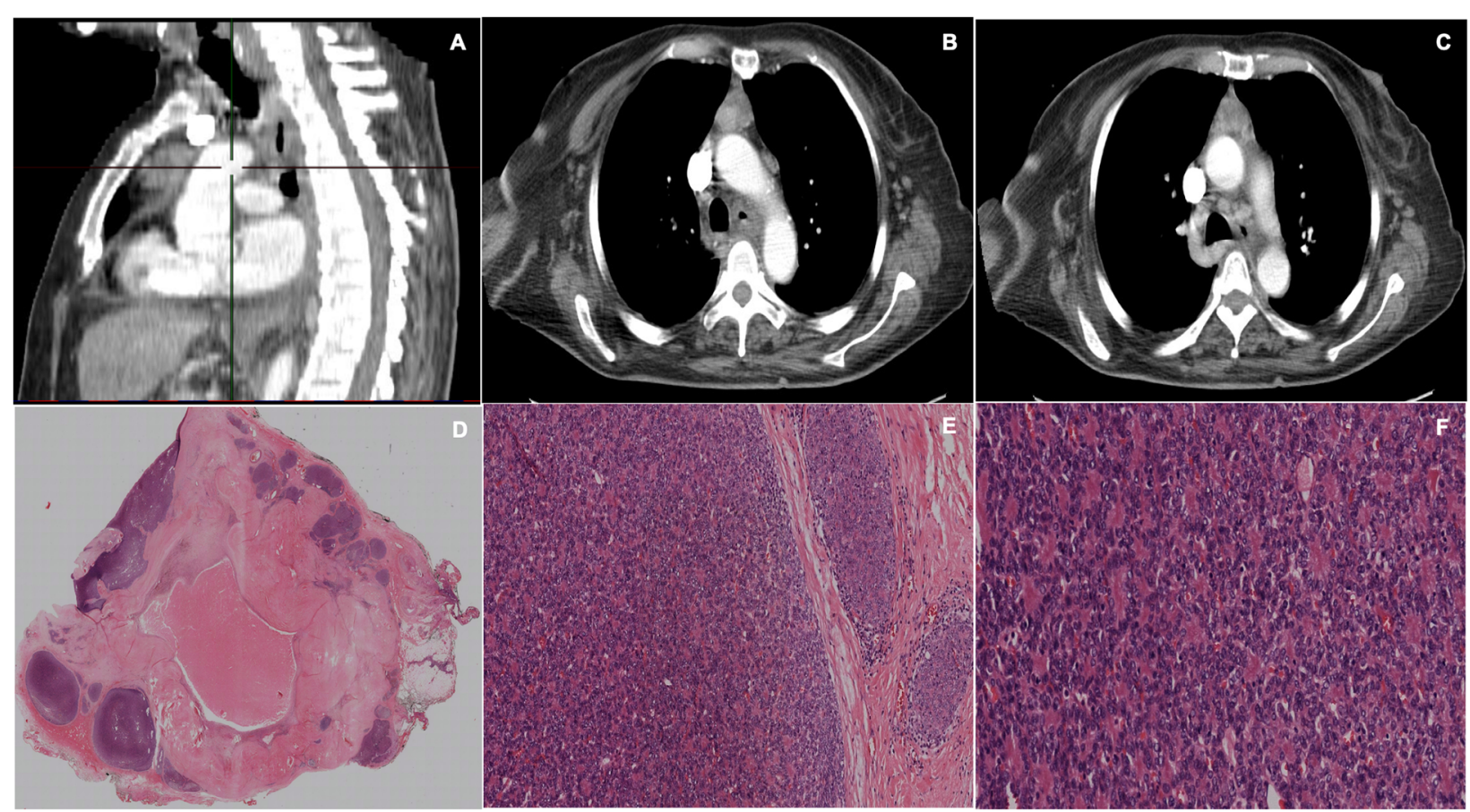

Fig. 1 Chest CT scan. a, b, c coronal reconstruction. d, e, f. Sagittal scans. A well-defined mass of lobulated contours is observed, which compromises the anterior mediastinum towards the right hemithorax and extends in the cephalon-caudal direction towards the cardio phrenic recess on the ipsilateral side. It is homogenous, with soft tissue densify and it enhances with contrast medium. It is $13 \times 10 \times 15 \mathrm{~cm}$, with few calcifications, and in close contact with the ascending aorta. There is a fatty plane between the superior vena cava and the mass

Table 2 Masaoka-Koga, TNM staging and histological diagnosis of patients

\begin{tabular}{ll}
\hline Masaoka-koga & $\mathbf{( N = 1 7 )}$ \\
\hline age I & $13(76.4 \%)$ \\
Stage II & $0(0 \%)$ \\
Stage III & $1(6.2 \%)$ \\
Stage IV & $3(17.6 \%)$ \\
TNM staging system & $\mathbf{( N = 1 7 )}$ \\
Stage I (T1a,b NOM0) & $13(76.4 \%)$ \\
Stage II (T2NOM0) & $1(6.2 \%)$ \\
Stage IIIA (T3NOM0) & $0(0 \%)$ \\
Stage IIIB (T4NOM0) & $0(0 \%)$ \\
Stage IVA (Any T, N1M0/ Any TNO-1M1a) & $0(0 \%)$ \\
Stage IVB (Any T, N2MO-M1a/ Any T, Any N, M1b) & $3(17.6 \%)$ \\
Histological diagnosis & $\mathbf{( N = 1 8 )}$ \\
Thymoma & $\mathbf{1 3}(\mathbf{7 2 . 2} \%)$ \\
$\quad$ Type A & $4(30.8 \%)$ \\
Type AB & $2(15.4 \%)$ \\
Type B1 & $6(46.1 \%)$ \\
Type B2 & $1(7.7 \%)$ \\
Thymic neuroendocrine tumors & $2(11.1 \%)$ \\
Thymic carcinoma & $1(5.5 \%)$ \\
Thymolipoma & $1(5.5 \%)$ \\
Thymic cyst & $1(5.5 \%)$ \\
\hline
\end{tabular}

\section{Surgical resection}

None of the cases had a biopsy performed prior to the surgical resection, which was done by thoracoscopy in 12 cases $(66.6 \%)$, sternotomy in 5 patients $(27.8 \%)$ and thoracotomy was performed in 1 case $(5.5 \%)$. There were no intra or postsurgical complications, particularly pneumothorax or phrenic nerve lesion. Median blood loss was retrieved for 16 patients, with a median of $75 \mathrm{cc}$ (IQR 262.5). In 16 cases (89\%) treatment consisted solely of surgical resection; 2 cases required additional therapy: one received chemotherapy after surgery and another required chemotherapy plus whole brain radiotherapy for brain metastasis.

\section{Histological findings}

Histopathological study found 13 cases $(72.2 \%)$ to be thymomas (type $\mathrm{A}$ in $30.8 \%$, type $\mathrm{AB} 15.4 \%$, type $\mathrm{B} 1$ $46.1 \%$, type B2 $7.7 \%$ ); 2 neuroendocrine tumors (11.1\%), 1 thymic carcinoma (5.5\%), 1 thymolipoma $(5.5 \%)$ and 1 thymic cyst (5.5\%) (Table 2), (Figs. 2, 3, 4, 5, 6, 7, 8, 9, 10).

\section{Clinical outcomes}

Mean hospital admission length was 11.9 days; 3.3 days corresponded to intensive care unit (ICU) admission. There was only one mortality during hospitalization. After 1 month of surgery, 12 patients (66.6\%) reported a significant clinical improvement during the follow up 

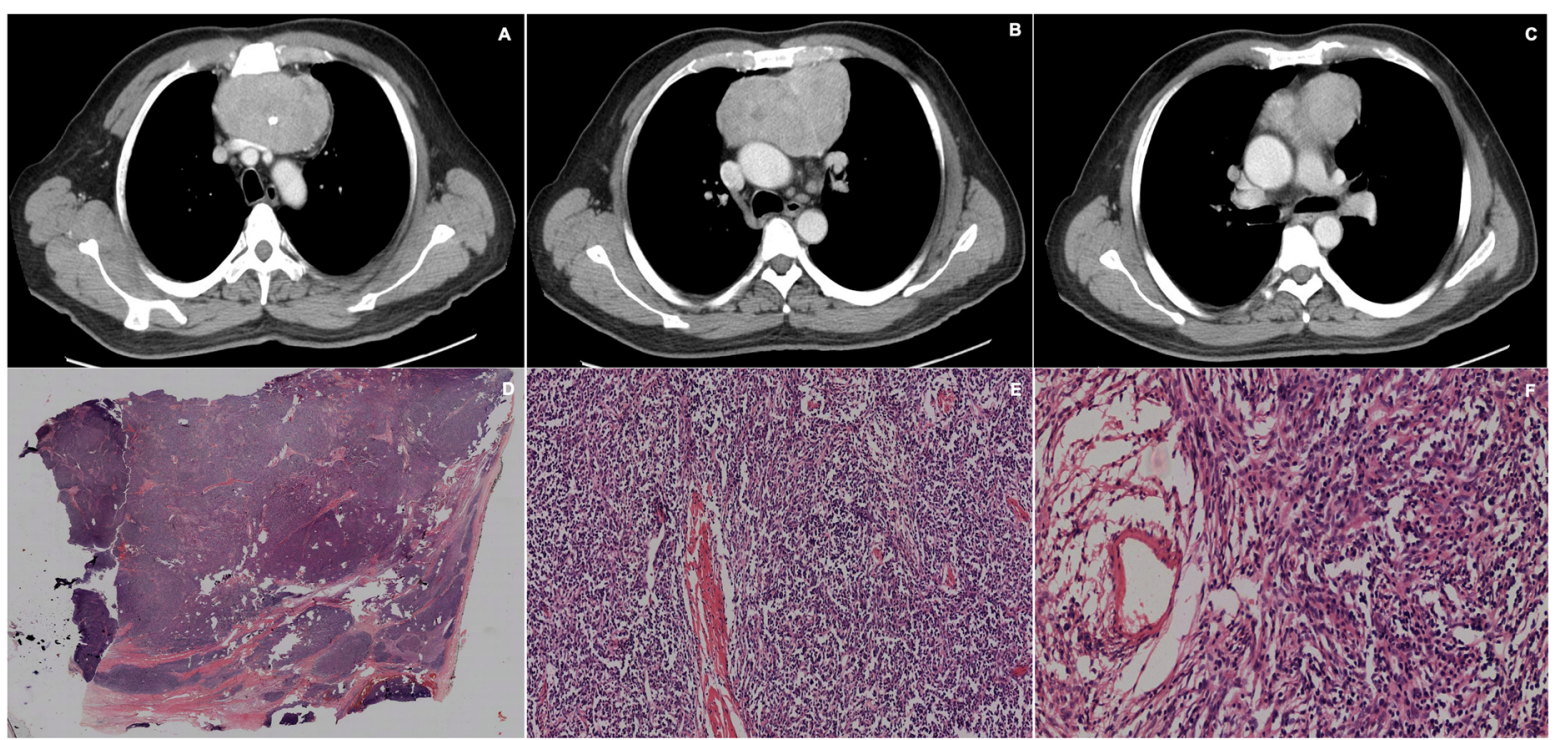

Fig. 2 a, b, c. Chest $C T$ scan showing a lobulated, well-defined contoured mass in the anterior mediastinum, which appears to be made up of multiples, smaller masses that coalesce giving a heterogeneous appearance. It has dystrophic calcifications in the center. The lesion partially compresses the left venous brachycephalic trunk. There is no compromise of the adjacent fat and had a cleavage plane with the vascular structures and soft tissues. D, E, F. H\&E staining, at 2x, $10 x$ and 20x magnification, displaying an encapsulated mass consisting of nodules separated by fibrous septa. The cells that occupy the nodules are of two types; cohesive, large and fusiform and lymphocytes. The predominant component is epithelial tissue, forming nodules and tassels, although there are also foci rich in lymphocytes. No Hassall corpuscles are observed, cystic zones or atypia. The lesion focally crosses the capsule but is not seen to compromise fat. A minimally invasive thymoma type $\mathrm{A}$ of $12 \mathrm{~cm}$ in diameter is diagnosed

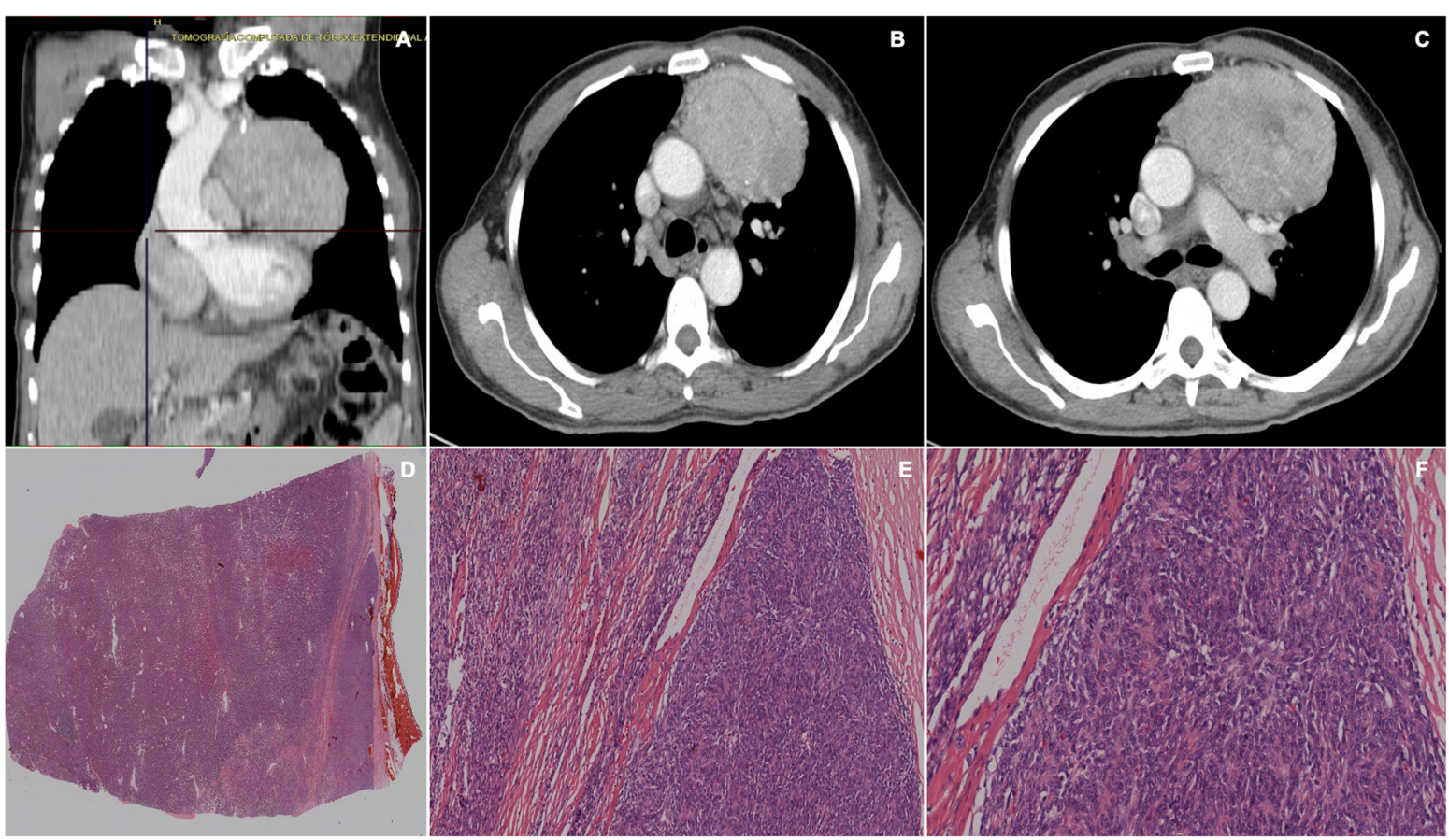

Fig. 3 a, b, c Chest CT scan, coronal and sagittal scans showing a large mass of irregular contours with poorly defined edges and diffuse changes in density with hypodense areas compatible with fat or necrosis, and others with calcifications. The mass is $14.2 \times 10.6 \times 9 \mathrm{~cm}$, located in the prevascular space, descending through the left para-aortic region towards the pulmonary aortic window. It compresses the pulmonary veins, displaces the aorta to the left and the trachea towards the right but does not alter its caliber. $\mathbf{d}, \mathbf{e}, \mathbf{f} \mathrm{H} \& \mathrm{E}$ staining, evaluated at 4x, 10x and $20 \mathrm{x}$, showing very dense and lobulated proliferation of lymphocytes. The lobes are variable in size and separated by fibrous septa. There are Hassall corpuscles and also light areas that remind the medullary areas of the thymus. Atypical areas are not observed. A thymoma type A is diagnosed 


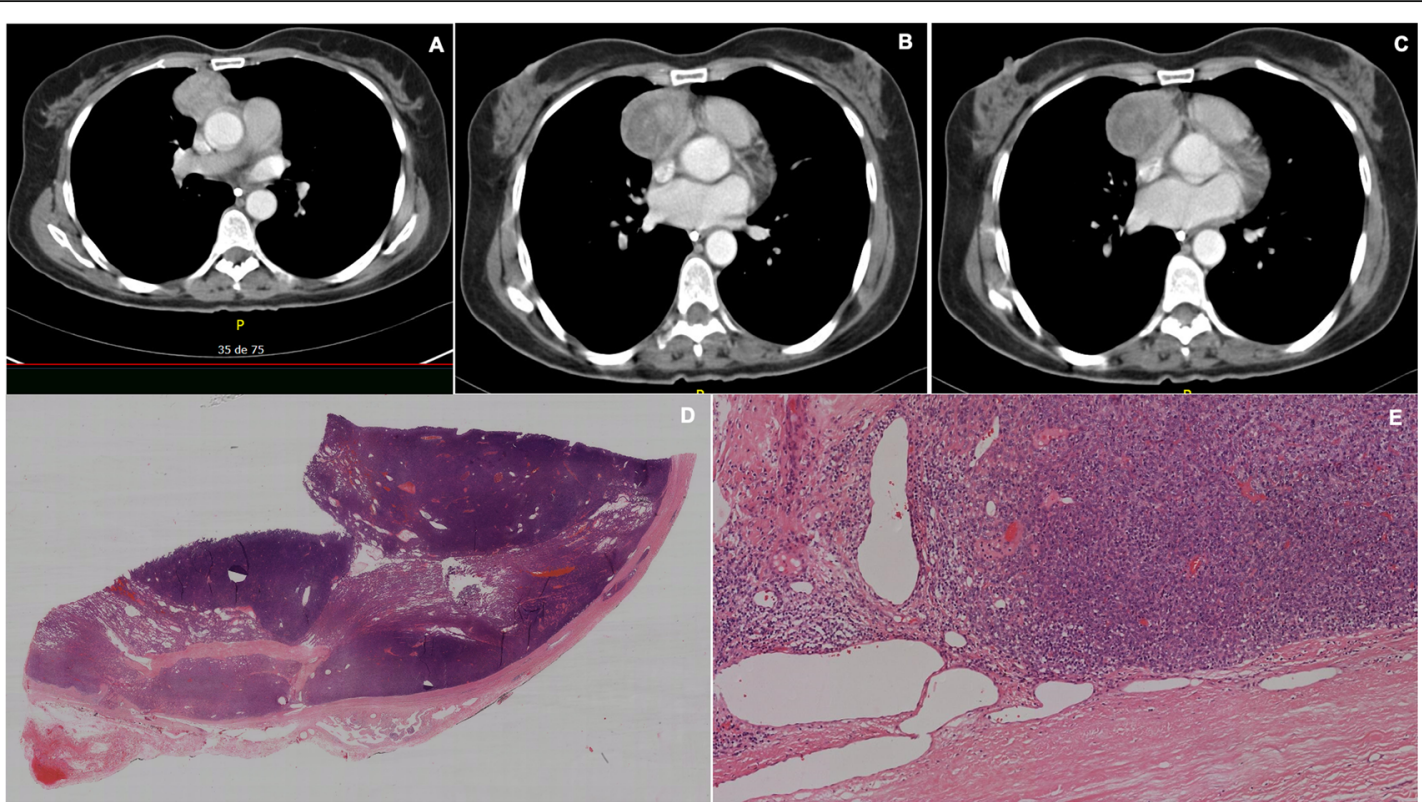

Fig. 4 a, b, c Chest CT scan showing a mass of $5 \times 4.5 \times 5.4 \mathrm{~cm}$, heterogeneous, located in the anterior mediastinum that produces posterior displacement of the right atrium, with areas than enhance with contrast and others with a necrotic aspect. $\mathbf{d}$, e h\&e staining, magnification at $2 x$ and 10x, showing a lesion consisting of a mixture of 2 populations: large cohesive cells with vesicular nuclei and small and uniform cells, lymphoid in appearance, with areas that resemble the normal functioning thymus and others similar to the medullary region. Large cells are oval with a pale rounded nucleus and small nucleolus and are inconspicuously distributed among a population of lymphocytes. The lesions form large nodules separated by thick fibrous septa and is surrounded by a collagen capsule. The lesion does not exceed the capsule. Diagnosis of type B1 thymoma

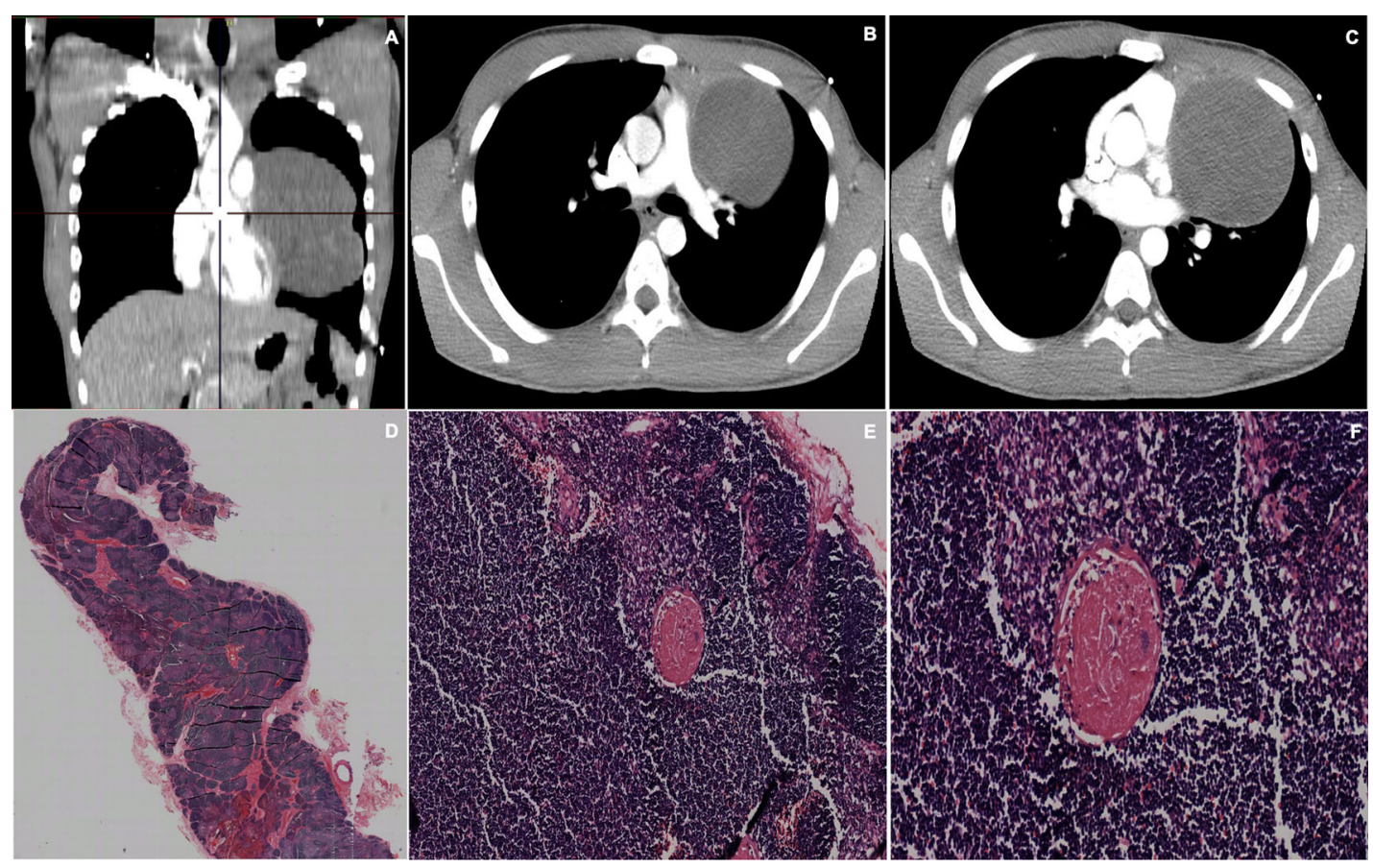

Fig. $\mathbf{5}$ a, b, c Chest CT scan were a lesion of heterogenous density with predominance of soft tissue is observed. There is a liquid component inside, multilobulated septa, with well-defined observed. It is enhanced with the contrast medium, rejects the pericardium deforming it and compresses the left source bronchus and contacts the chest wall. The lesion is $13 \times 9 \times 8.5 \mathrm{~cm}$. $\mathbf{d}, \mathbf{e}, \mathbf{f} \mathrm{f} \& \mathrm{E}$ staining, magnification at $4 \mathrm{x}, 10 \mathrm{x}$, and 20x showing proliferation of small, dense lymphocytes, organized in lobes, Hassall's corpuscles and clear areas reminiscent of the thymic medullary area consistent with a cortical thymoma type B1 


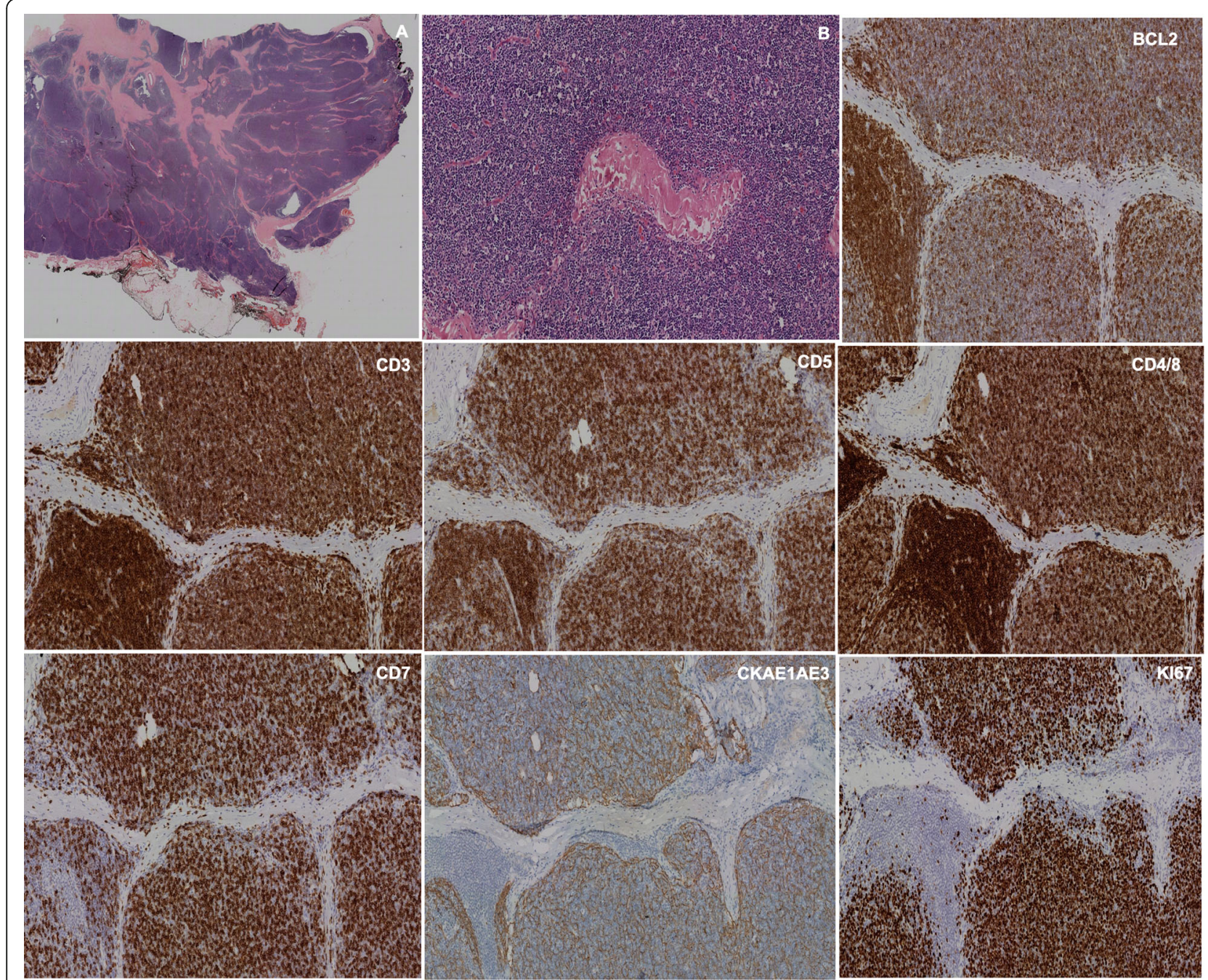

Fig. $\mathbf{6}$ a, b H\&E staining, with $10 x$ and 20x magnification. A pseudoencapsulated thymic lesion with fibrous septa and lymphocytic cellularity is observed. It is small in size, with conspicuous nucleolus and mitotic activity adopting a diffuse distribution pattern. With immunehistochemistry, expression is observed for T-line lymphocytes with TdT, BCL2, CD3, CD5, CD4/8 and CD7. (No representation of B line with CD20). No expression for CD15, CD30, CD117, CD56 or CD57. The epithelial weave is clearly observed with CKAE1/AE3. The rate of cell proliferation valued by Ki-67 is $80 \%$ with 5 mitoses per field of high power when studied with $\mathrm{pHH} 3$. It was diagnosed as a type B1 thymoma

visit with the thoracic surgeon. The remaining 6 patients (33.3\%) reported no change in their symptoms. The first patient had surgery on January 2011 and the last patient on May 2019, they were all followed until December 2019. Three patients died overall, and 5 patients were lost to follow up. A Kaplan-Meier curve was performed, estimating a survival probability of $81 \%$ at 5 years (Fig. 11).

\section{Discussion}

As reported in the literature worldwide, the frequency of thymic tumors in both Latin America and Colombia is low; in fact, only 105 patients with thymomas were included in the multicenter study CLICaP-LATimus, [9] which was carried out from 1997 to 2018 in 7 Latin
American countries (Mexico, Costa Rica, Colombia, Ecuador, Brazil, Peru and Argentina). In Colombia, a recent publication by Buitrago et al. reported 31 patients with thymic tumors who were treated at the National Institute of Cancerology (INC) between 2006 and 2017 [10].

The population described in our study was predominantly masculine, inconsistent with the gender distribution reported in the CLICaP-LATimus and the INC studies, were the proportion was inverted (40\% men and $60 \%$ woman) $[9,10]$. However, the mean age (52.7 years) was similar to the previous studies, unlike what has been reported in international cohorts, such as the European RARECAREnet projects $(2000-20,007)$ [11] or the Japanese publication by Kanemura et al., [12] in which patients were on average a decade older at diagnosis. 


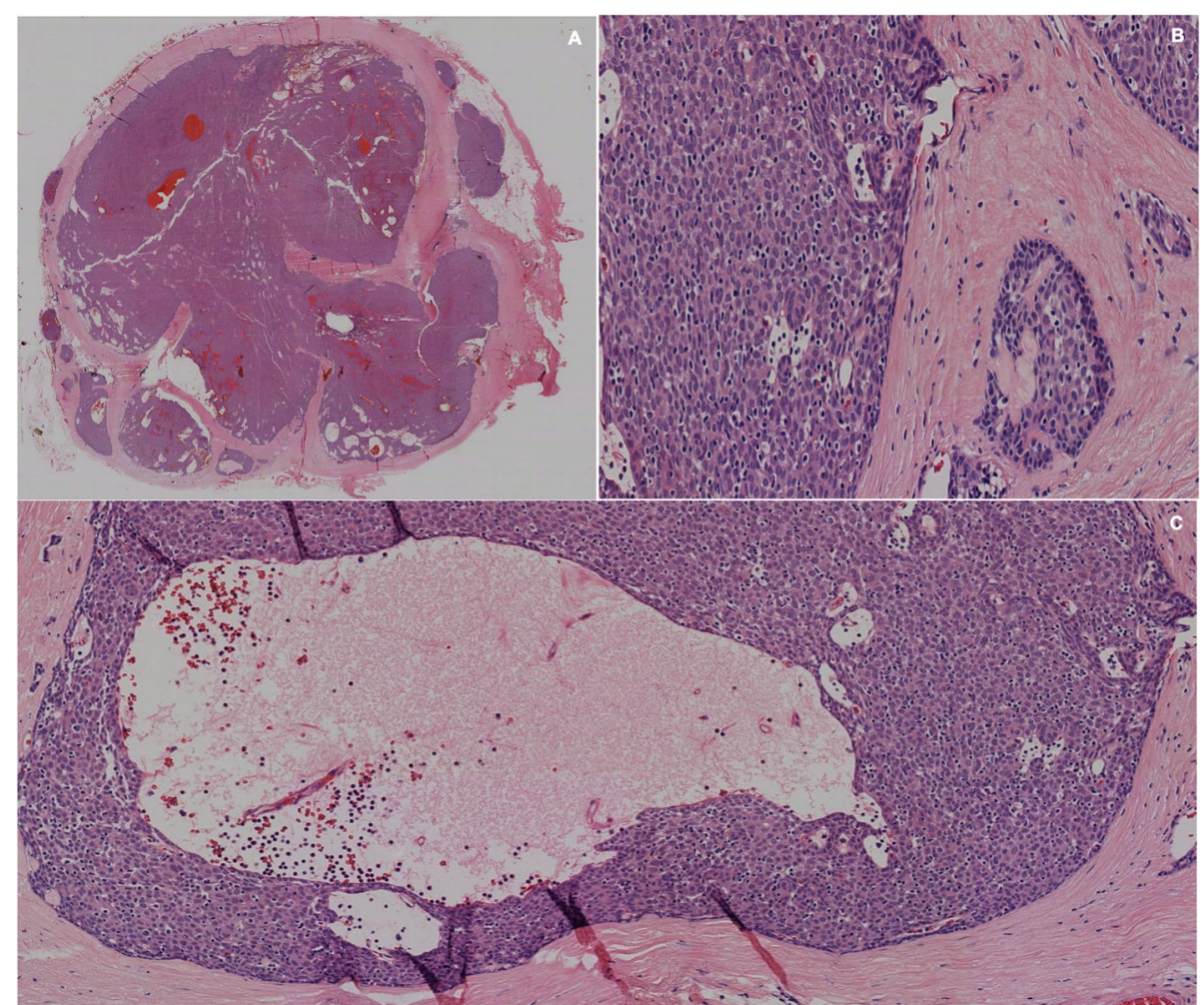

Fig. 7 a, b, c H\&E staining evaluated at 4x, 10x and 20x, corresponding to a delimited, capped lesion of thymic origin, composed of cells with squamous differentiation. There are no Hassall corpuscles. The lesion consists of large epithelial cells with presence of lymphocytes between them. Diagnosis of thymoma with squamous differentiation type B1/B2 is made

Inconsistent with previous evidence, $83.4 \%$ of patients were symptomatic at diagnosis, being dyspnea the most frequent manifestation. In this study, we found that $27.7 \%$ of patients presented with paraneoplastic syndromes, consistent with the frequency reported in the literature of 30-50\% [6]. Furthermore, paraneoplastic neuromuscular syndromes (myasthenia gravis, Eaton-Lambert syndrome, myotonic dystrophy, myositis, neuromyotonic, limbic encephalitis and stiff-person syndrome) are the most common similar to our findings, but hematological (RBC aplasia and pancytopenia), endocrine, dermatological and rheumatological disorders are also prevalent [6].

Symptomatic patients are more likely to have a chest image, facilitating diagnosis. Although a contrast enhanced chest computed tomography (CT) is the image of choice (Fig. 1), [7] cardiac or chest nuclear magnetic resonance imaging (NMRI) is useful in distinguishing compression from vascular invasion, in large lesions were this could be difficult to determine by CT. NMRI also allows the evaluation of the phrenic nerves and gives additional information about the involvement of the chest wall [13-15].

The National Comprehensive Cancer Network $(\mathrm{NCCN})$ guidelines divide thymic cancers into three categories, according to the possibility of surgical resection.
A total thymectomy and complete excision of the tumor without further treatment is the recommendation for TNM stage I tumors. When capsular invasion is present (stage II-IV) postoperative radiotherapy should be considered. For locally advanced tumors, the possibility of resection should be carefully considered by an experienced multidisciplinary team, and multimodal treatment with chemotherapy and/or radiotherapy is warranted [16]. In our study $89 \%$ patients were managed with surgery alone, leaving no residual tumor, including 13 patients with stage I cancer, 1 patient with stage II (T2NOM0) and 1 patient with stage IVB (T3N2M0). The 2 remaining patients, who had separate pleural metastasis (T4N2M1a) and extrathoracic metastasis (T4N2M1b) affecting the brain, also underwent surgery but were offered additional oncologic treatment.

There are different surgical approaches to radical thymectomy, including cervicotomy, thoracotomy, sternotomy, video-assisted thoracoscopic surgery (VATS) (Fig. 9), and robotic assisted thoracoscopic surgery (RATS). All soft tissue should be removed in the anterior mediastinum between the phrenic nerves, which is key to control patients who present with myasthenia gravis and has been shown to positively impact mortality [17, 18]. Although the standard surgical technique is median sternotomy, since it 


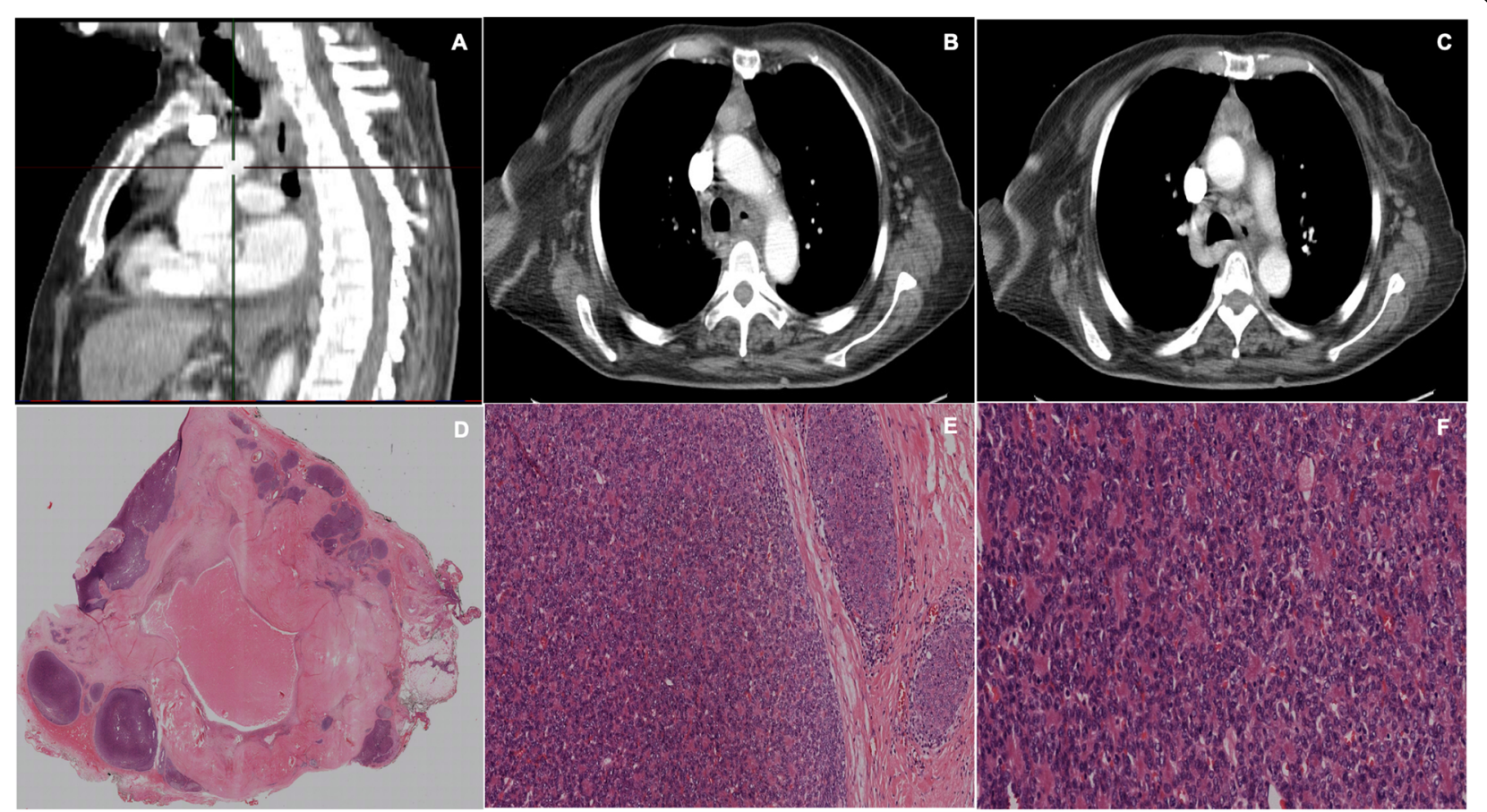

Fig. 8 a, b, c Chest CT scan, 1 coronal and 2 sagittal cuts, showing a small mass localized in the anterior mediastinum with well-defined borders, heterogeneous density, without invading o compressing structures. D, E, F. Hematoxylin and eosin (H\&E) staining, it is observed at 2x, 10x and 20x showing uniform cells, with little pleomorphism, cytoplasm in moderate quantity that form large solid nodules, separated by dense fibrous tissue. In some of these nodules, the tumor cells form well-differentiated rosettes. Diagnosis of an atypical carcinoid tumor originating in the thymus

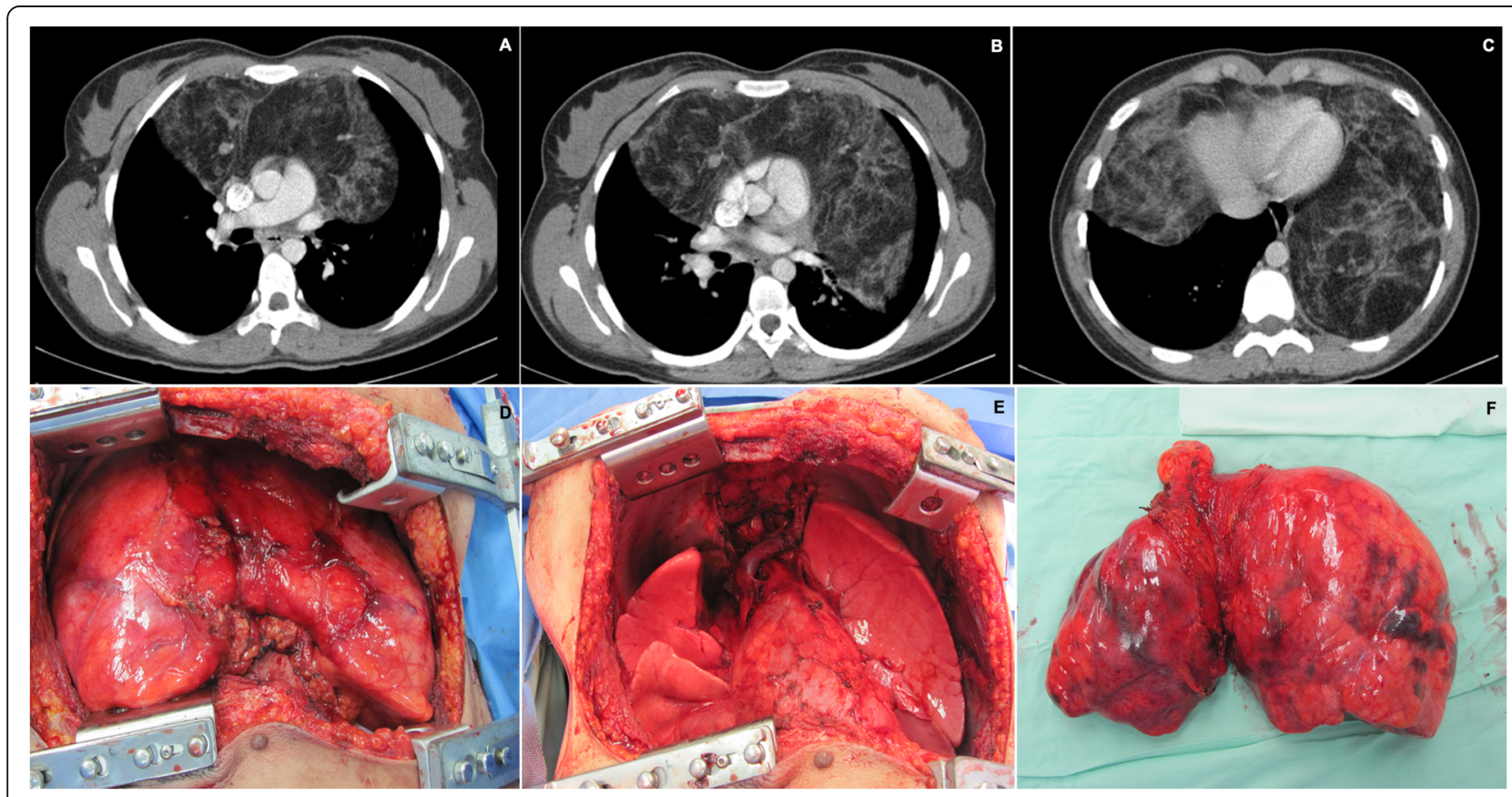

Fig. 9 a, b, c Chest CT scan showing a $15 \times 17 \times 21 \mathrm{~cm}$ mass in the anterior mediastinum, with heterogeneous density. The fat content of welldefined edges that surrounds the cardio mediastinum predominates without infiltrating it and extends to the left and right thoracoabdominal area. $\mathbf{d}$ Appearance of the large tumor in the mediastinum, smooth, bilobed prior to enucleation. E. The heart, lungs and large vessels are observed after resecting the tumor lesion that had no infiltration to neighboring structures. e Macroscopic aspect of the resected lesion that had a histological diagnosis of thymolipoma 


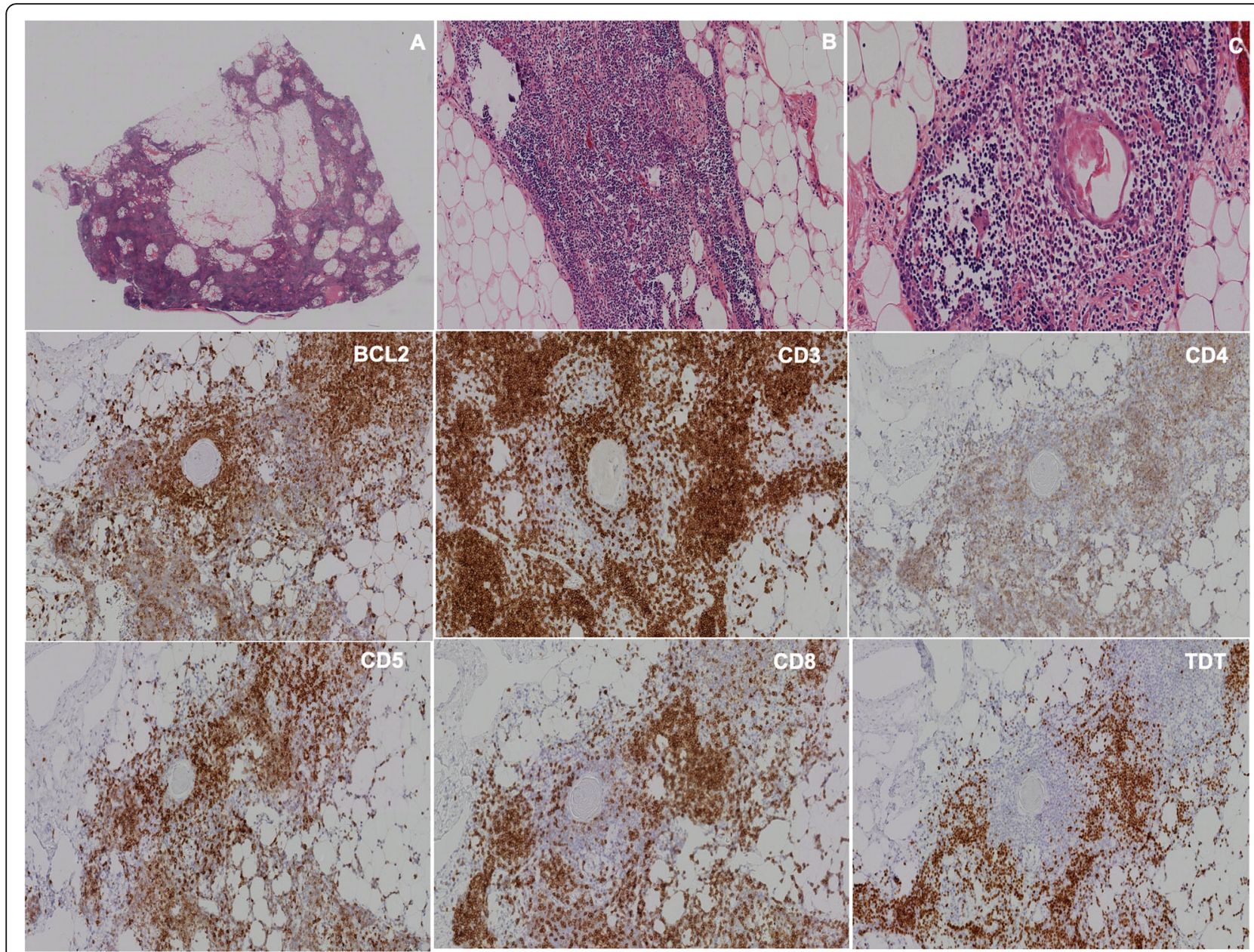

Fig. 10 a, b, c H\&E staining, magnification of 4x, 10x and 20x, showing an encapsulated mesenchymal lesion were the mature adipose tissue predominates. There is thymic tissue, composed by cortex and medulla with Hassall corpuscles. With immunohistochemistry, there is expression in thymic lymphocytes for CD3, CD4, CD5, CD8, TdT and BCL2 (there is no expression for CD15 or CD20). It was diagnosed as a capped thymolipoma

allows a complete visualization of the mediastinum, pleural spaces, presence of capsular invasion or infiltration of near-by structures, VATS has been gaining popularity given that it is a minimally invasive procedure $[17,19]$. VATS has been proved consistently to deliver best perioperative outcomes compared to open surgery, due to a reduced blood loss, shorter surgical time and hospitalization, better pain management and fewer postoperative infections. However, the oncological results of VATS are still controversial regarding the completeness of resection and recurrence rates, therefore its use is widely accepted for early stage thymomas (Masaoka-Koga I, II) [19]. Nevertheless, Ning Xu et al., published a retrospective case report of 4 patients with stage III thymic tumors with invasion of the superior vena cava (SVC), who underwent VATS plus partial SVC resection without presenting major perioperative or postoperative complications, no mortality nor recurrence after 14 months of follow-up. These findings could be replicated by experienced centers worldwide giving hope to minimally invasive strategies [20]. In our patients, thoracoscopy was the most utilized approach in $66.6 \%$ of cases. In our experience there were no intra or post operatory complications, even in patients who underwent sternotomy and thoracotomy.

Definitive diagnosis was made after surgical intervention in most cases, as in our patients, since the use of biopsy is only contemplated when there is suspicion of a differential diagnosis such as germ cell tumor or goiter [21]. The World Health Organization (WHO) described a histopathological classification for thymomas, thymic carcinomas, thymic neuroendocrine tumors, among others. Specifically for thymomas, which are the most frequent, they are classified as type A, atypical type A variant, type $\mathrm{AB}$, type $\mathrm{B} 1-\mathrm{B} 3$, micronodular thymoma with lymphoid stroma (MNT), metaplastic thymoma and other rare thymomas such as microscopic thymoma, sclerosing thymoma and lipofibroadenoma (Table 3) [22]. In our experience, thymomas were the most common 


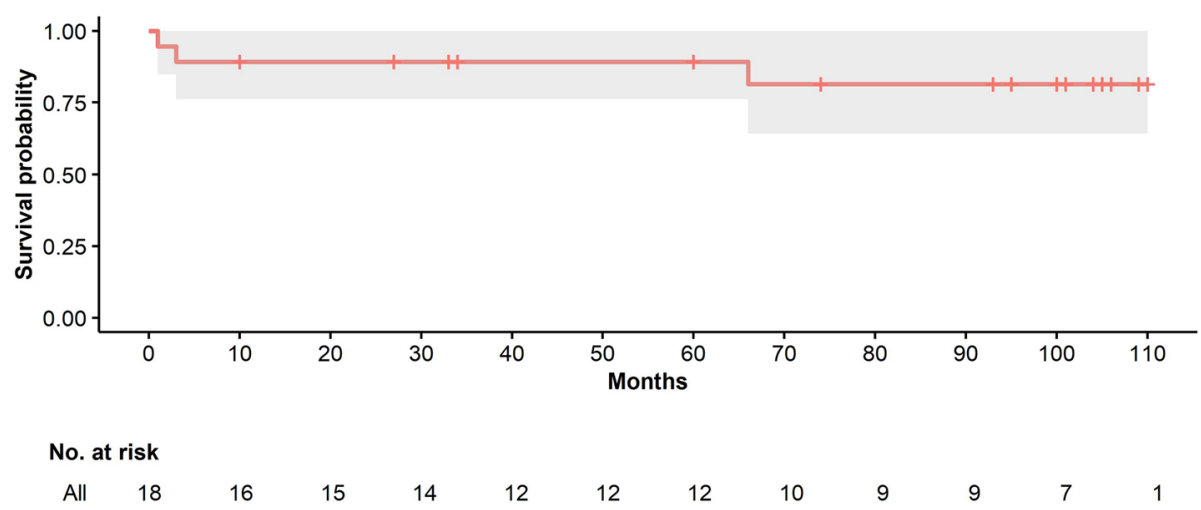

Fig. 11 Kaplan-Meier survival estimate in patients with thymic tumors. Kaplan Meier curve showing the 5 year survival rate for these patients

histopathological finding (72.2\%), similar to the INC study which reported thymomas in $70.9 \%$ of cases [10]. Our most frequent subtype was B1 (46.1\%) followed by type A (30.8\%).

Long-term survival of thymic tumors, particularly thymomas, tends to be favorable after radical resection. A retrospective analysis of 62 patients with thymomas who underwent thymectomy, reported an overall 5- and 10-year survival rate of 85.36 and $78.20 \%$, respectively. In this cohort, patients $<50$ years old, early Masaoka stages (I and II), histological type (type $A, A B, B 1$ ) and lack of recurrence were independent prognostic factors of survival [23]. In our experience, survival rate at 5 years was $81 \%$, similar to the study cited earlier. We had three mortalities, of which 2 had disseminated disease.

\section{Conclusion}

Thymic tumors are unusual in the general population but represent half of tumors affecting the anterior mediastinum, of which thymomas are the most common. The treatment of choice is radical thymectomy, which has been shown to positively impact patient mortality. Although open surgery is the standard approach, VATS has been shown to be a safe and efficacious procedure and should be considered for this group of patients. While evidence suggests the majority of patients are asymptomatic, this was not our experience, facilitating

Table 3 World Health Organization (WHO) histological classification of thymomas

\begin{tabular}{|c|c|c|}
\hline Thymoma subtype & Obligatory criteria & Optional criteria \\
\hline Type A & $\begin{array}{l}\text { Occurrence of bland, spindle shaped epithelial cells (at least focally); } \\
\text { paucity }{ }^{\mathrm{a}} \text { of absence of immature }(T d T+) T \text { cells throughout the tumor }\end{array}$ & Polygonal epithelial cells CD20+ epithelial cells \\
\hline Atypical type A variant & $\begin{array}{l}\text { Criteria of type A thymoma; in addition: comedo-type tumor necrosis; } \\
\text { increased mitotic count }\left(>4 / 2 \mathrm{~mm}^{2}\right) \text {; nuclear crowding }\end{array}$ & Polygonal epithelial cells CD20+ epithelial cells \\
\hline Type AB & $\begin{array}{l}\text { Occurrence of bland, spindle shaped epithelial cells (at least focally); } \\
\text { abundance of immature }(T d T+) T \text { cells focally or throughout the tumor }\end{array}$ & Polygonal epithelial cells CD20+ epithelial cells \\
\hline Type B1 & $\begin{array}{l}\text { Thymus-like architecture and cytology: abundance of immature T cells, } \\
\text { areas of medullary differentiation (medullary islands); paucity of } \\
\text { polygonal or dendritic epithelia cells without clustering ( }<3 \text { contiguous } \\
\text { epithelial cells) }\end{array}$ & Hassall's corpuscles; perivascular spaces \\
\hline Type B2 & $\begin{array}{l}\text { Increased numbers of single or c lustered polygonal or dendritic epithelial } \\
\text { cells intermingled with abundant immature T cells }\end{array}$ & $\begin{array}{l}\text { Medullary islands; Hassall's corpuscles; } \\
\text { perivascular spaces }\end{array}$ \\
\hline Type B3 & $\begin{array}{l}\text { Sheets of polygonal slightly to moderately atypical epithelial cells; absent } \\
\text { or rare intercellular bridges; paucity or absence of intermingled TdT+ T cells }\end{array}$ & Hassall's corpuscles; perivascular spaces \\
\hline$M N T^{b}$ & $\begin{array}{l}\text { Nodules of bland spindle or oval epithelial cells surrounded by an } \\
\text { epithelial cell free lymphoid stroma }\end{array}$ & $\begin{array}{l}\text { Lymphoid follicles; monoclonal B cells and/or } \\
\text { plasma cells (rare) }\end{array}$ \\
\hline Metaplastic thymoma & $\begin{array}{l}\text { Biphasic tumor composed of solid areas of epithelial cells in a background } \\
\text { of bland-looking spindle cells; absence of immature T cells }\end{array}$ & $\begin{array}{l}\text { Pleomorphism or epithelial cells; actin, keratin } \\
\text { or EMA-positive spindle cells }\end{array}$ \\
\hline Rare others ${ }^{c}$ & & \\
\hline
\end{tabular}


early diagnosis and possibly increasing the survival probability of our patients.

\section{Abbreviations}

CT: Computed tomography; NCCN: National Comprehensive Cancer Network: RBC: Red blood cell; TNM staging: Tumor, nodule, metastasis staging; MK: Masaoka-Koga; IOR: Interquartile range; ICU: Intensive care unit: INC: National Institute of Cancerology; NMRI: Nuclear Magnetic Resonance Imaging; VATS: Video-assisted thoracoscopic surgery; WHO: World Health Organization; MNT: Micronodular thymoma with lymphoid stroma.; SVC: Superior vena cava

\section{Acknowledgements}

Not applicable.

\section{Data permissions}

Administrative permits were not required to access the raw data prior to analysis within this study.

\section{Authors' contributions}

All authors have read and approved the manuscript, and significantly contributed to this paper. DFSG, EIM, LFS, MV, SS, LFT: Conception and design, literature review, manuscript writing and correction, final approval of manuscript.

\section{Funding}

No funding sources were used.

\section{Availability of data and materials}

All data and material are available for sharing if needed with the Corresponding Author.

\section{Ethics approval and consent to participate}

This manuscript was written in compliance with the ethical standards of the institutional ethics committee and with the 1964 Helsinki Declaration. We have approval of the Ethics Committee in Biomedical Research from Fundación Valle del Lili. This is supported in letter No. 260 of 2019. Act No. 15 of 2019, which is available if needed with the Corresponding Author. Consent to participate does not apply to this retrospective case study, approval was obtained from the ethics committee.

\section{Consent for publication}

Informed consent does not apply to this retrospective case study, approval was obtained from the ethics committee.

\section{Competing interests}

The authors declare that they have no competing interests. This manuscript has not been published and is not under consideration for publication elsewhere. Additionally, all of the authors have approved the contents of this paper and have agreed to the journal's submission policies.

\footnotetext{
Author details

${ }^{1}$ Department of Internal Medicine, Faculty of Health Sciences, Universidad Icesi, Calle 18 \# 122-135, Cali 7600032, Colombia. ²Department of Internal Medicine, Pulmonology Service, Fundación Valle del Lili, Carrera 98 \# 18-49, Cali 7600032, Colombia. ${ }^{3}$ Faculty of Health Sciences, Universidad Icesi, Calle 18 \# 122-135, Cali 7600032, Colombia. ${ }^{4}$ Department of Pathology and Laboratory Medicine, Fundación Valle del Lili, Carrera 98 \# 18-49, Cali 7600032, Colombia. ${ }^{5}$ Department of Surgery, Thoracic Surgery Service, Fundación Valle del Lili, Carrera 98 \# 18-49, Cali 7600032, Colombia. ${ }^{6} \mathrm{Clinica}$ Research Center, Fundación Valle del Lili, Carrera 98 \# 18-49, Cali 7600032, Colombia. ${ }^{7}$ Department of Internal Medicine, Pulmonology Service, Interventional Pulmonology, Fundación Valle del Lili, Avenida Simón Bolívar. Carrera 98 \# 18-49, Tower 6, 4th Floor, 7600032 Cali, Colombia.
}

Received: 26 July 2020 Accepted: 16 February 2021

Published online: 16 March 2021

\section{References}

1. Travis WD, Brambilla E, Muller-Hermelink HK, Harris CC. World Health Organization Classification of Tumours. Pathology and Genetics of Tumours of theLung, Pleura, Thymus and Heart. Lyon: IARC Press; 2004.

2. Engels EA, Pfeiffer RM. Malignant thymoma in the United States: demographic patterns in incidence and associations with subsequent malignancies. Int J Cancer. 2003;105(4):546-51.

3. Duwe BV, Sterman DH, Musani Al. Tumors of the mediastinum. Chest. 2005; 128(4):2893-909.

4. Patterson GA. Thymomas. Semin Thorac Cardiovasc Surg. 1992:4(1):39-44

5. Scorsetti M, Leo F, Trama A, D'Angelillo R, Serpico D, Macerelli M, et al. Thymoma and thymic carcinomas. Crit Rev Oncol Hematol. 2016;99:332-50.

6. Chen J, Yang Y, Zhu D, Chen G, Wei S, Qiu X, et al. Thymoma with pure red cell aplasia and Good's syndrome. Ann Thorac Surg. 2011;91(5):1620-2.

7. Regnard JF, Zinzindohoue F, Magdeleinat P, Guibert L, Spaggiari L, Levasseur $P$. Results of re-resection for recurrent thymomas. Ann Thorac Surg. 1997;64(6):1593-8.

8. Bushan $\mathrm{K}$, Sharma S, Verma H. A review of thymic tumors. Indian J Surg Oncol. 2013:4(2):112-6.

9. Mas L, Patané A, Arrieta OG, et al. Survival of Thymoma is extensive in LatinAmerican patients: results from over 10 years of experience (CLICaPLATimus). J Thorac Surg. 2019;14(11):S1177-8.

10. Buitrago-Ramírez MR, Mantilla-Gaviria HJ, Carreño Dueñas JA. Tumores del timo: Experiencia del Instituto Nacional de Cancerología de Colombia. Rev Colomb Cancerol. 2019;23(3):92-8.

11. Siesling S, Van der Zwan JM, Izarzugaza I, et al. Rare thoracic cancers, including peritoneum mesotelioma. Euro J Cancer. 2012;48(7):949-60.

12. Kanemura H, Tamura T, Nishimura N, et al. Thymic epithelial tumor treatment in Japan: analysis of hospital cancer registry and insurance claims data, 2012-2014. Jpn J Clin Oncol. 2020;50(3):310-17.

13. Lichtenberger JP, Reynolds DA, Keung J, Keung E, Carter BW. Metastasis to the heart: a radiologic approach to diagnosis with pathologic correlation. AJR Am J Roentgenol. 2016;207(4):764-72.

14. Carter BW, Benveniste MF, Truong MT, Marom EM. State of the art: MR imaging of Thymoma. Magn Reson Imaging Clin N Am. 2015;23(2):165-77.

15. Rosado-de-Christenson ML, Strollo DC, Marom EM. Imaging of thymic epithelial neoplasms. Hematol Oncol Clin North Am. 2008;22(3):409-31.

16. National Comprehensive Cancer Network. Thymomas and Thymic Carcinomas (Version 2.2019). https://www.nccn.org/professionals/physician_ gls/pdf/thymic.pdf. Accessed 20 Jan 2020.

17. Di Crescenzo VG, Napolitano F, Panico C, et al. Surgical approach in thymectomy: our experience and review of the literature. Int J Surg Case Rep. 2017;39:19-24. https://doi.org/10.1016/j.ijscr.2017.07.028.

18. León Atance P, González Aragoneses F, Moreno Mata N, et al. Timectomía en la miastenia gravis [Thymectomy in myasthenia gravis]. Arch Bronconeumol. 2001;37(5):235-9. https://doi.org/10.1016/s0300-2896(01 )75060-0.

19. Raveglia F, Bertolaccini L, Solli P, et al. VATS thymectomy: oncological results and comparison between minimally invasive strategies. Shanghai Chest. 2018;2:1. https://doi.org/10.21037/shc.2018.01.03.

20. Xu N, Gu Z, Ji C, Zhang X, Chen T, Fang W. Thoracoscopic thymectomy with partial superior vena cava resection for locally advanced thymomas. Thorac Dis. 2019;11(2):438-44. https://doi.org/10.21037/jtd.2018.12.120.

21. Hakiri S, Kawaguchi K, Fukui T, Nakamura S, Ozeki N, Mori S, et al. Verification of the diagnostic strategy for anterior mediastinal tumors. Int $J$ Clin Oncol. 2018;0(0):0

22. Marx A, Chan JK, Coindre JM, et al. The 2015 World Health Organization classification of tumors of the Thymus: continuity and changes. J Thorac Oncol. 2015;10(10):1383-95. https://doi.org/10.1097/JTO.0000000000000654.

23. Koçer B, Kaplan T, Günal N, et al. Long-term survival after RO resection of thymoma. Asian Cardiovasc Thorac Ann. 2018;26(6):461-6. https://doi.org/1 $0.1177 / 0218492318778634$

\section{Publisher's Note}

Springer Nature remains neutral with regard to jurisdictional claims in published maps and institutional affiliations. 